\title{
Structural Evaluation and Photocatalytic Performance of Chemically Synthesised ZnO Nanoparticles
}

\author{
BANAJIT MALAKAR, ABU TALEB MIAH, \\ CHINMOY KALITA and PRANJAL SAIKIA*
}

Department of Applied Sciences (Chemical Science Division), Gauhati University Institute of Science and Technology, Guwahati-781014, Assam, India

psjorhat@gmail.com

Received 11 April 2015 / Accepted 18 May 2015

\begin{abstract}
This paper presents the achievability of removal of basic dye methylene blue (MB) from aqueous solutions by using homogeneous $\mathrm{ZnO}$ nanoparticles prepared by a very feasible modified chemical route. The prepared nanomaterial was characterized by Thermogravimetry, X-ray diffraction, Photoluminiscence, FT-Infra Red and UV-Vis Spectroscopy, and Transmission Electron Microscopy analyses. The morphology of the nanoparticles were found to be very homogeneous with particle size of around $20 \mathrm{~nm}$. The dye degradation was monitored with UV-Vis Spectrophotometer and the photodegradation phenomenon followed pseudo first order kinetics.
\end{abstract}

Keywords: Nanomaterials, Characterization, Photocatalysis, Chemical Synthesis, Dye degradation

\section{Introduction}

With the increasing health concern, in recent years, there has been a tremendous growth in research to find out effective measures for the removal of hazardous materials such as dyes and organic compounds from waste water ${ }^{1,2}$. In this regard, nano Zinc oxide $(\mathrm{ZnO})$ is emerging as a promising photocatalyst due of its high catalytic efficiency, inexpensiveness and non-toxicity ${ }^{3}$. Infact, semiconductor metal oxide nanomaterials have attracted much more attention due to their utility not only as efficient electron mediators for the photocatalytic degradation ${ }^{4}$ but also their applications in gas sensors, ${ }^{5}$ lithium storage ${ }^{6}$ and water-splitting ${ }^{7} . \mathrm{ZnO}$ is an n-type semiconductor with wide and direct bandgap $(\mathrm{Eg}=3.37$ $\mathrm{eV}$ at room temperature), high exciton binding or Rydberg energy (60 meV at room temperature), unique optical and luminescence properties ${ }^{8,9}$. Due to the presence of oxygen vacancies that in turn impart superior conducting properties, nanostructured $\mathrm{ZnO}$ can be utilized efficiently as a photocatalyst towards degradation of organic dye pollutant ${ }^{10,11}$. Moreover, it has high quantum efficiency, high redox potential, advanced physical and chemical stability ${ }^{12}$. Semiconductors upon illumination with solar or UV light source, produces electron/hole pairs, where electrons are promoted to the conduction band leaving behind positive holes in the valence band. In presence of surface oxygen vacancies, the 
generated electron/hole pairs could initiate a series of reactions by reacting with surface bound hydroxyl groups $\left(\mathrm{OH}^{-}\right)$or $\mathrm{O}_{2}$ from water resulting in the formation reactive radicals like $\mathrm{O}_{2}$, $\mathrm{OH}^{*}$ that significantly contribute in the complete degradation of organic pollutants in water ${ }^{13}$.

As size and shape dependence is a very crucial property of nanomaterials, various methods have been employed for the synthesis of $\mathrm{ZnO}$ nanostructures with different shapes and properties ${ }^{14}$. Based on shape, numerous $\mathrm{ZnO}$ nanostructures have been reported, such as nanoparticles $^{15}$, nanorods ${ }^{16}$, nanocombs ${ }^{17}$, nanowires ${ }^{18}$, nanotubes ${ }^{19}$, nanoflowers ${ }^{20}$, etc. Among these, $\mathrm{ZnO}$ nanoparticle with the presence of oxygen vacancy can effectively reduce Methylene Blue (MB) dye in water ${ }^{21}$. MB, also known with the chemical name tetramethylthionine chloride, was the first synthetic drug used in medicine and was used for the treatment of malaria ${ }^{22,23}$. It is a phenothiazine cationic dye and a monoamine oxidase inhibitor (MAOI) ${ }^{24}$. Infusion of $\mathrm{MB}$ at doses exceeding $5 \mathrm{mg} / \mathrm{kg}$ results in combination of MB with any selective serotonin reuptake inhibitors like duloxetine, sibutramine, venlafaxine, clomipramine, imipramine and may precipitate serious serotonin toxicity, serotonin syndrome ${ }^{25}$. It affects the 5-hydroxytryptamine system and causes dizziness, headache, tremors, seizures and mental confusion ${ }^{26,27}$. Noteworthy that $\mathrm{MB}$ is hard to degrade. Therefore, degradation of MB in water do deserves serious attention.

In the present work, we report an economical and facile route for the synthesis of $\mathrm{ZnO}$ nanoparticle. This method uses low-temperature and avoids harsh reaction condition. Another aspect of the present study is to evaluate the photocatalytic activity of the $\mathrm{ZnO}$ nanoparticles for waste water treatment.

\section{Experimental}

Zinc acetate dihydrate was purchased from Sigma Aldrich with the purity of $98 \mathrm{wt} \%$ and was used as precursor. Ethanol and sodium hydroxide pellets were purchased Merck. Analytical reagent methylene Blue dye was supplied by HiMedia. All the chemicals were used as purchased without further purification. Deionised distilled water obtained from Millipore system was used in the preparation of solutions.

\section{Preparation of $\mathrm{ZnO}$ nanoparticles}

$\mathrm{ZnO}$ nanoparticles materials were prepared by direct precipitation method described by Borghei et al., ${ }^{15}$ with some modifications. In a typical synthetic procedure, solution of equal volume of Zinc acetate dihydrate and sodium hydroxide were prepared separately in distilled deionized water at a ratio of the concentrations 1:2 (zinc acetate dehydrate : sodium hydroxide). Then the synthesis was carried out by drop-wise addition of sodium hydroxide solution to the zinc acetate dihydrate solution under vigorous stirring at room temperature, to form a transparent white solution. The solution mixture was allowed to react for 5 hours so as to slowly produce the $\mathrm{ZnO}$ particles. The precipitates obtained from the reaction mixture is collected and washed with distilled deionized water and then with ethanol several times using centrifugation. The washed precipitates were dried in an electric oven at $100{ }^{\circ} \mathrm{C}$, by keeping it overnight to form $\mathrm{ZnO}$ precursor. Following this, the precursors were calcinated at $400{ }^{\circ} \mathrm{C}$ for $4 \mathrm{~h}$ to form $\mathrm{ZnO}$ nanoparticle.

Preparation of reaction set-up for photocatalytic degradation of methylene blue using $\mathrm{ZnO}$ nanoparticle

In this study, degradation of $30 \mathrm{~mL}$ of $10 \mathrm{ppm}$ methylene blue (MB) dye solution at 120 minutes was investigated using the $0.2 \mathrm{~g} \mathrm{~L}^{-1}$ of as-synthesized $\mathrm{ZnO}$ nanoparticle. The MB dye solution and catalyst was taken in a round bottom flux. To establish the adsorption 
equilibrium between the dye molecules and the catalyst surface, the mixture was stirred in dark for 20 minutes. The solution was then irradiated with solar light. The decolourization efficiency (\%) was calculated as follows:

$$
\% \text { Degradation }=\left[\left(\mathrm{A}_{0}-\mathrm{A}_{\mathrm{t}}\right) / \mathrm{A}_{0}\right] \times 100
$$

Where $A_{0}$ is the initial absorbance of dye and $A_{t}$ is the absorbance of dye at time ' $t$ ' after photo-irradiation. The photocatalytic reduction reaction was carried out for $120 \mathrm{~min}$ as no further degradation was observed after that. The catalyst was recovered by centrifugation to study the effectiveness of the recovered catalyst. The reaction was studied under solar light in summer season between $11 \mathrm{AM}$ and $3 \mathrm{PM}$ during which fluctuation of solar intensity is minimum ${ }^{28}$.

\section{Characterization of materials}

The powder X-ray diffraction (XRD) patterns were recorded on a Rigaku Multiflex instrument for $2 \theta$ values from $10-80^{\circ}$ using nickel-filtered $\mathrm{CuK} \alpha(0.15418 \mathrm{~nm})$ radiation source and a scintillation counter detector. Thermogravimetric analysis was done using a Mettlar Toledo TG-SDTA instrument where the samples were heated up to $1000{ }^{\circ} \mathrm{C}$ at a heating rate of $10{ }^{\circ} \mathrm{C} / \mathrm{min}$. Infra-red spectra were measured using a FT-IR spectrophotometer, Model Spectrum Two FT-IR Spectrometer (Perkin Elmer). Measurements were achieved by pelletizing the samples with $\mathrm{KBr}$ in the mid-infrared region at an accelerating voltage of $200 \mathrm{~V}$. Transmission Electron Micrographs (TEM) were captured with JEOL JEM 2100 TEM instrument operated at $200 \mathrm{kV}$. UV-spectrums were recorded using UV-Vis spectrophotometer (Model-Perkin Elmer Lambda 35). Photoluminiscence (PL) spectra were recorded by Hitachi F-2500, fluorescence spectrometer.

\section{Results and Discussion}

\section{XRD analysis}

Figure 1 represents XRD pattern of synthesized $\mathrm{ZnO}$ nanoparticle. The XRD pattern shows diffraction peaks at $2 \theta=31.6^{\circ}, 34.2^{\circ}, 36.1^{\circ}, 47.3^{\circ}, 56.3^{\circ}, 62.7^{\circ}, 66.2^{\circ}, 67.5^{\circ}, 68.8^{\circ}, 72.4^{\circ}$ and $77.2^{\circ}$ belong to the (100), (002), (101), (102), (110), (103), (200), (201), (004) and (202) planes respectively, which corresponds to the hexagonal wurtzite structure of ZnO (JCPDS No. 36-1451) $)^{29}$.

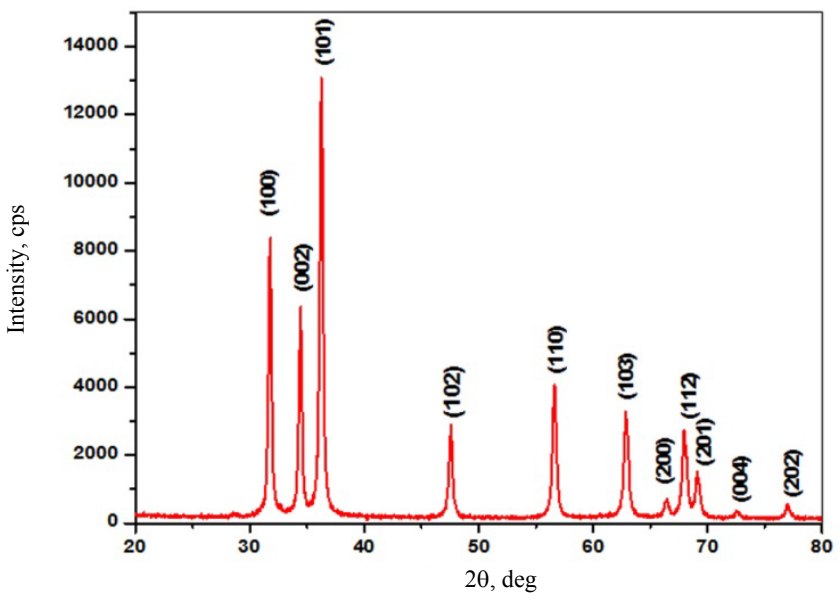

Figure 1. X-Ray diffraction pattern of $\mathrm{ZnO}$ nanoparticle 
In the XRD analysis, no prominent peak for any other phase was found, which reveals the high purity of the synthesized product.

\section{TG analysis}

Thermal stability of the synthesised material was investigated with the help of thermogravimetric analysis. The temperature suitable for calcinations of the sample could be chosen on the basis of this analysis. The temperature at which mass loss was stabilised was regarded as the suitable calcinations temperature. As presented in Figure 2, three distinct mass loss features are observed. One feature at around $80-100{ }^{\circ} \mathrm{C}$ was due to the loss of molecularly absorbed water from surface. Another weight loss feature in the range $150-220^{\circ} \mathrm{C}$ could be primarily due to the loss of nondissociative adsorbed water as well as water held on the surface by hydrogen bonding. The sample exhibited one major weight loss peak in the range $250-400{ }^{\circ} \mathrm{C}$ due to the loss impurities from the bulk. Above that, no further weight loss was observed. Therefore, the calcinations temperature for the sample was chosen to be $400{ }^{\circ} \mathrm{C}$. The stabilization in weight loss after $400{ }^{\circ} \mathrm{C}$ implies that Zinc hydroxides are completely converted to $\mathrm{ZnO}$ nanoparticles after calcination. Moreover, it could be inferred that the synthesized $\mathrm{ZnO}$ nanoparticles are thermally quite stable at high temperatures (up to $\left.1000{ }^{\circ} \mathrm{C}\right)^{30}$.

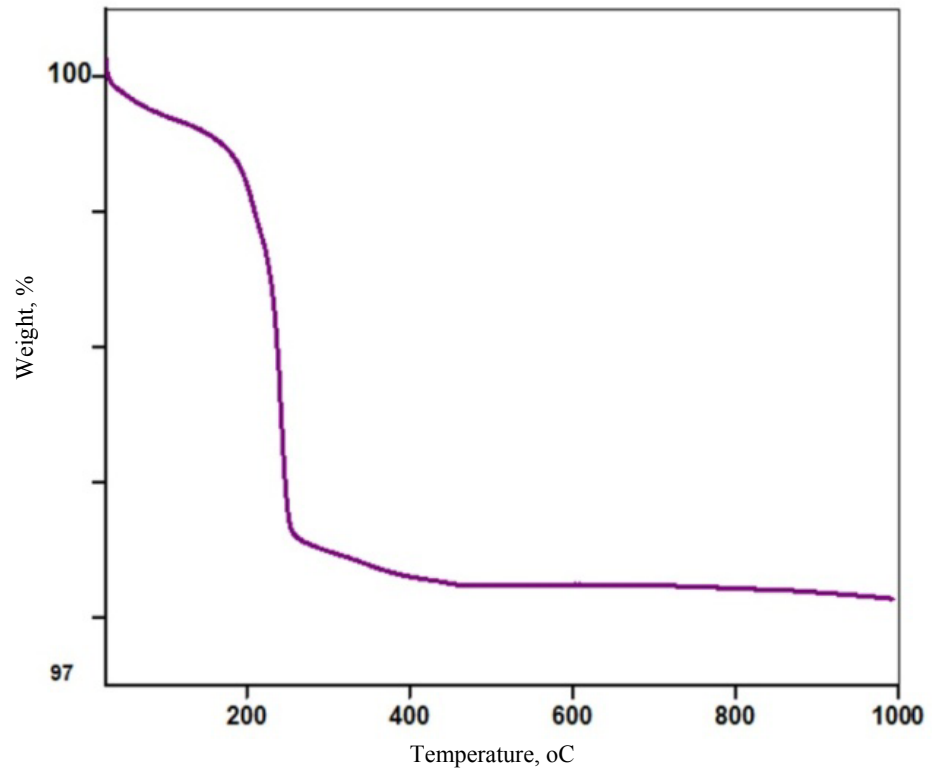

Figure 2. TGA profile of $\mathrm{ZnO}$ nanoparticle

\section{FT-IR analysis}

Fourier Transform Infrared spectra of Zinc oxide nanoparticles were recorded in the frequency range $400-4000 \mathrm{~cm}^{-1}$ by preparing $\mathrm{KBr}$ pellet and operating at a resolution of $4 \mathrm{~cm}^{-1}$. The FT-IR spectra for $\mathrm{ZnO}$ nanoparticles is shown in Figure 3. A strong band at $\sim 3446 \mathrm{~cm}^{-1}$ is due to surface adsorbed $\mathrm{O}-\mathrm{H}$ stretching mode of vibration in $\mathrm{ZnO}$ nanoparticle and the characteristic stretching band for $\mathrm{Zn}-\mathrm{O}$ is observed at $\sim 439 \mathrm{~cm}^{-1}$. The peaks at $\sim 1650 \mathrm{~cm}^{-1}$ may be due to the presence of water molecules in $\mathrm{KBr}$, which is used in the preparation of sample for FT-IR analysis ${ }^{31}$. 


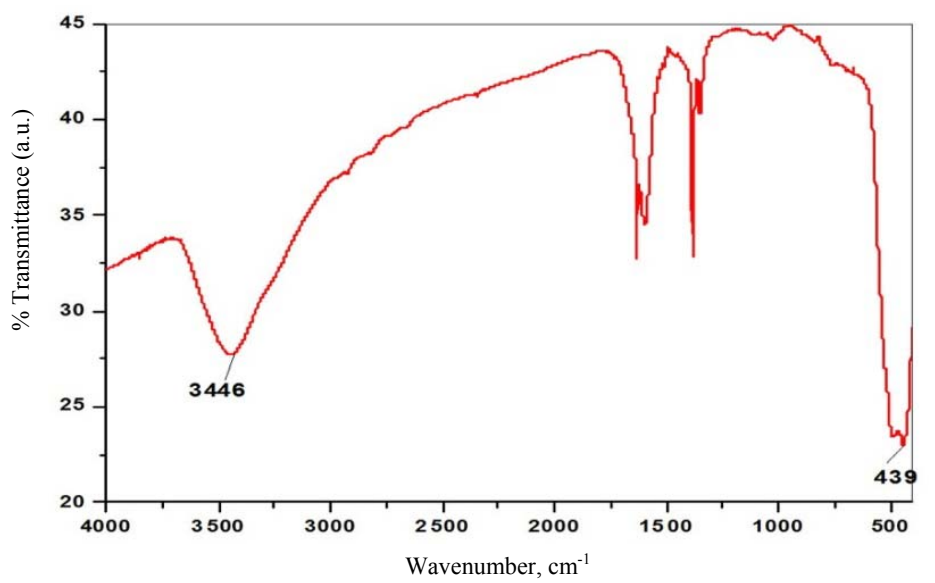

Figure 3. FT-IR spectra of $\mathrm{ZnO}$ nanoparticle

\section{TEM analysis}

The HRTEM image of $\mathrm{ZnO}$ nanoparticle is shown in Figure 4. The particle sizes are in the range of $20 \mathrm{~nm}$ and imply that the shapes are almost spherical in nature (Figure 4a and $4 \mathrm{~b}$ ). The particles are homogeneous in nature which would be crucial for showing better catalytic activity. The selected area electron diffraction (SAED, Figure 4a) reveals the good crystalline nature of the material. The measured lattice spacing from HRTEM micrograph (Figure $4 \mathrm{c}$ ) was found to be $0.30 \mathrm{~nm}$ corresponding to the (100) plane of hexagonal $\mathrm{ZnO}^{32}$.

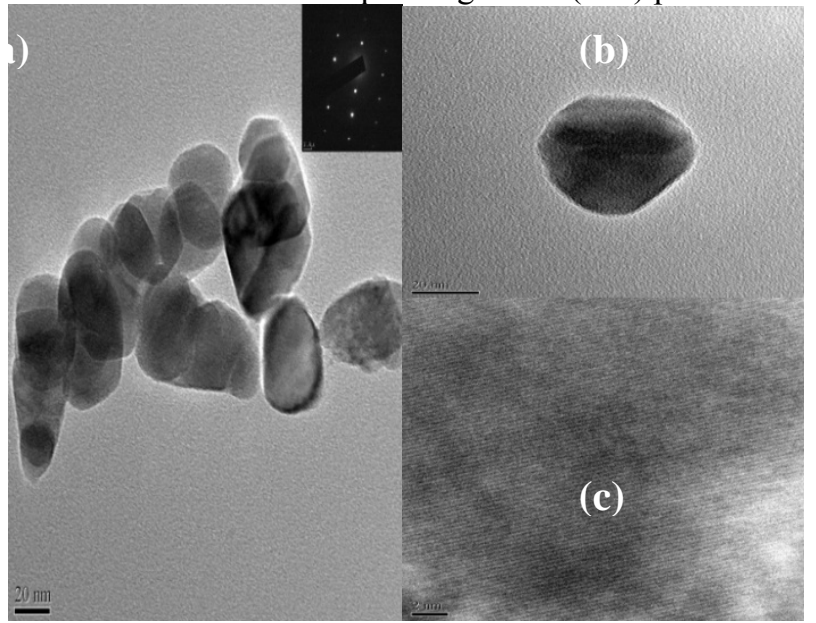

Figure 4. TEM image of (a)as prepared $\mathrm{ZnO}$, (b) single $\mathrm{ZnO}$ nanoparticle, (c) HRTEM image for $\mathrm{ZnO}$

\section{PL analysis}

Figure 5 shows the Photoluminescence (PL) emission from the prepared $\mathrm{ZnO}$ nanoparticles dispersed in double distilled water. The $\mathrm{ZnO}$ nanoparticle shows an ultraviolet (UV) emission at about $390 \mathrm{~nm}$ and defect related band within 480-700 $\mathrm{nm}$ range. Moreover, a minor peak at $445 \mathrm{~nm}$ (blue) and a strong maximum major peak at $\sim 565 \mathrm{~nm}$ (green wavelength) are observed. UV emission originates from the free exciton recombination related 
to near-band-edge (NBE) emission. Reports suggest that generally the proposed visible emissions are associated with deep level (DL) defect(s) causing the emission. Color from $\mathrm{ZnO}$ film are mainly due to the intrinsic defects such as oxygen vacancies $\left(V_{O}\right)$, zinc vacancies $\left(V_{Z n}\right)$, interstitial oxygen $\left(\mathrm{O}_{\mathrm{i}}\right)$, interstitial zinc $\left(\mathrm{Zn}_{\mathrm{i}}\right)$, antisite oxygen $\left(\mathrm{O}_{\mathrm{Zn}}\right)$ and antisite zinc $\left(\mathrm{Zn}_{\mathrm{O}}\right)$. The weak and broad blue emission band at $\sim 468 \mathrm{~nm}$ is due to the DL transition from $\mathrm{Zn}_{\mathrm{i}}$ to $\mathrm{V}_{\mathrm{Zn}}$ or Conduction Band (CB) to $\mathrm{V}_{\mathrm{Zn}}$, whereas green emission band at $\sim 565 \mathrm{~nm}$ is possibly due to the DL transition ${ }^{33,34}$ from $C B$ to $V_{O}$, or to $V_{Z n}$, or C.B. to both $V_{O}$ and $V_{Z n}$.

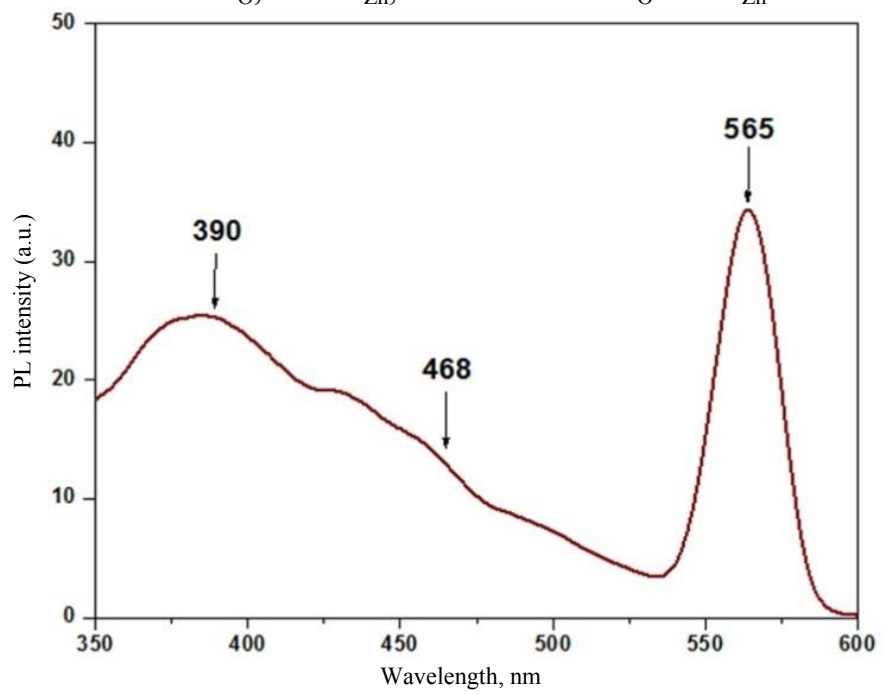

Figure 5. Room temperature PL spectra of $\mathrm{ZnO}$ nanoparticle

\section{UV-Visible spectral analysis ZnO nanoparticle}

The formation of Zinc oxide nanoparticle was studied by analysing it with UV-Visible Spectrophotometer in the range of 200-700 nm. Figure 6 shows the characteristic peak at $\sim 372 \mathrm{~nm}$ for $\mathrm{ZnO}$ nanoparticle ${ }^{35}$. The band gap value calculated from the spectrum was found to be $\sim 3.33 \mathrm{eV}$ that reinforces the semiconducting property of the material.

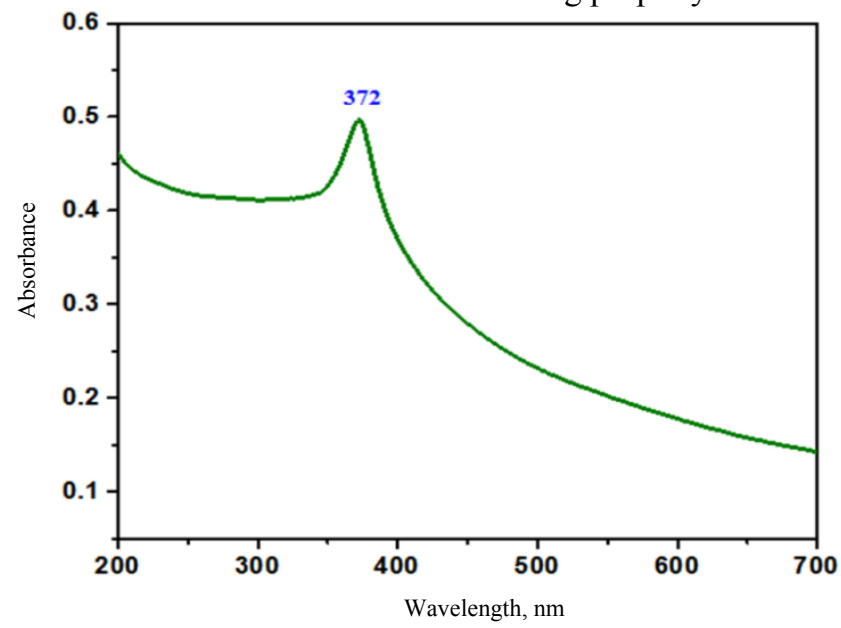

Figure 6. UV spectra of $\mathrm{ZnO}$ nanoparticle 


\section{Photocatalytic degradation of methylene Blue using $\mathrm{ZnO}$ nanoparticle mechanism}

The solar light induced photocatalytic activity of the synthesized $\mathrm{ZnO}$ is due to the electron promotion from the valance band to the conduction band of the semiconducting oxide resulting generation of electron-hole pairs as shown in equation (1). The valance band hole $\mathrm{h}^{+}(\mathrm{VB})$ is a region of positive charge which react with adsorbed water molecules and surface-bound hydroxyl groups $\left(\mathrm{OH}^{-}\right)$to generate hydroxyl radicals $\left(\mathrm{OH}^{*}\right)$ as shown in equations (2) and (3). The conduction band electron $\mathrm{e}^{-}(\mathrm{CB})$ is a region of negative charge that reduces the oxygen molecules present in the solution by forming a superoxide radical anion $\left(\mathrm{O}_{2}{ }^{-}\right)$as in equation (4). Hydroxyl radicals are known to be powerful oxidizing agents $\left(E_{o}=+3.06 \mathrm{~V}\right)^{36}$. During the photocatalytic process, MB was believed to be degraded through direct oxidation by the $\mathrm{OH}^{\cdot}$ radicals and $\mathrm{O}_{2}{ }^{--}$radicals as shown in equation (5) ${ }^{37}$. The possible reaction mechanism for photocatalytic degradation of MB dye using zinc oxide nanoparticle can be describe as follows:

$$
\begin{array}{ll}
\mathrm{ZnO}+h v & \rightarrow \mathrm{e}^{-}(\mathrm{CB})+\mathrm{h}^{+}(\mathrm{VB}) \\
\mathrm{h}^{+}(\mathrm{VB})+\mathrm{H}_{2} \mathrm{O} & \rightarrow \mathrm{H}^{+}+\mathrm{OH}^{\cdot} \\
\mathrm{h}^{+}(\mathrm{VB})+\mathrm{OH}^{-} & \rightarrow \mathrm{OH}^{\cdot} \\
\mathrm{e}^{-}(\mathrm{CB})+\mathrm{O}_{2} & \rightarrow \mathrm{O}_{2}^{--} \\
\mathrm{OH}^{-}+\mathrm{O}_{2}^{--}+\mathrm{MB} \text { dye } & \rightarrow \text { Degraded product }
\end{array}
$$

\section{Activity study}

To study the photocatalytic activity of $\mathrm{ZnO}$ nanoparticle under solar light source, experiments were carried out using $0.2 \mathrm{~g} \mathrm{~L}^{-1}$ of synthesized $\mathrm{ZnO}$ nanoparticle and $30 \mathrm{~mL}$ of $10 \mathrm{ppm} \mathrm{MB}$ dye with stirring time of 120 minutes. Figure $7 \mathrm{a}$ shows the UV-visible absorption spectra of $10 \mathrm{ppm} \mathrm{MB}$ aqueous solutions with $\mathrm{ZnO}$ photocatalyst following the irradiation with sun light for different durations of time. The characteristic absorption peak of $\mathrm{MB}$ at $662 \mathrm{~nm}$ is monitored as a function of sunlight exposure time and degradation of MB is studied at this particular characteristic peak using UV-spectrophotometer. As shown in inset of Figure 7a, the colour of MB dye changes from blue to colourless upon complete degradation. Figure $7 \mathrm{~b}$ shows degradation percentage of $\mathrm{MB}$ dye at different time interval. From Figure 7, degradation percentage of MB dye is calculated and found to be $96.16 \%$ in 120 minute. No further degradation MB dye was achieved after 120 minute.

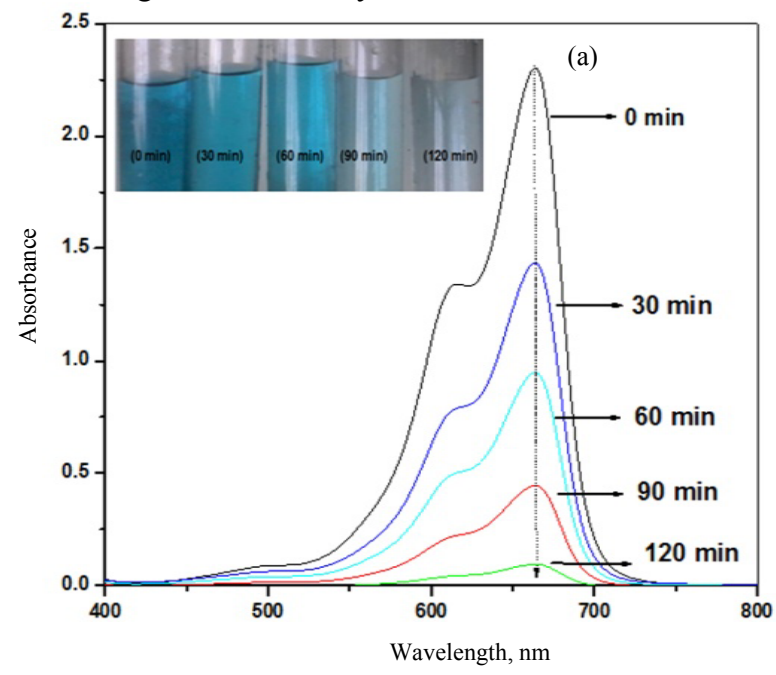




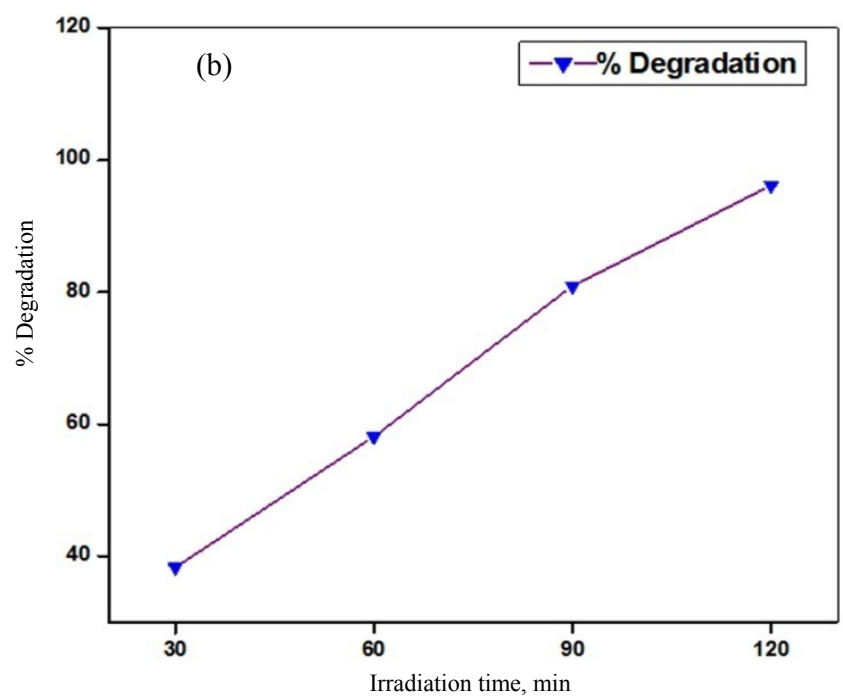

Figure 7. (a) UV spectra of MB dye Degradation using ZnO nanoparticle (b) \% degradation of $\mathrm{MB}$ dye w.r.t. time

Figure $8 \mathrm{a}$ and $8 \mathrm{~b}$ shows the kinetics study of $\mathrm{MB}$ dye degradation by using $\mathrm{ZnO}$ nanoparticle under solar-light exposure. To study the kinetics of the catalytic reaction the absorbance at $662 \mathrm{~nm}$ of the $\mathrm{MB}$ dye and $\mathrm{ZnO}$ mixed reaction solution was measured as a function of time. The plots of $\mathrm{C}_{\mathrm{t}} / \mathrm{C}_{0}$ and $\ln \left(\mathrm{C}_{0} / \mathrm{C}_{\mathrm{t}}\right)$ against the reaction time is shown in Figure $8 \mathrm{a}$ and $8 \mathrm{~b}$ respectively. The $\mathrm{C}_{0}$ and $\mathrm{C}_{\mathrm{t}}$ in the plots of $\mathrm{C}_{\mathrm{t}} / \mathrm{C}_{0}$ and $\ln \left(\mathrm{C}_{0} / \mathrm{C}_{\mathrm{t}}\right)$ against reaction time are the concentrations of $\mathrm{MB}$ dye at 0 and time, respectively. The kinetic curves for degradation of MG dye (Figure $8 \mathrm{~b}$ ) follows pseudo first order kinetics. From Figure $8 \mathrm{~b}$ the calculated apparent rate constant, $\mathrm{K}_{\mathrm{app}}\left(\mathrm{min}^{-1}\right)$ is found to be $0.026 \mathrm{~min}^{-1}$ and the $\mathrm{R}^{2}$ value is 0.957 .

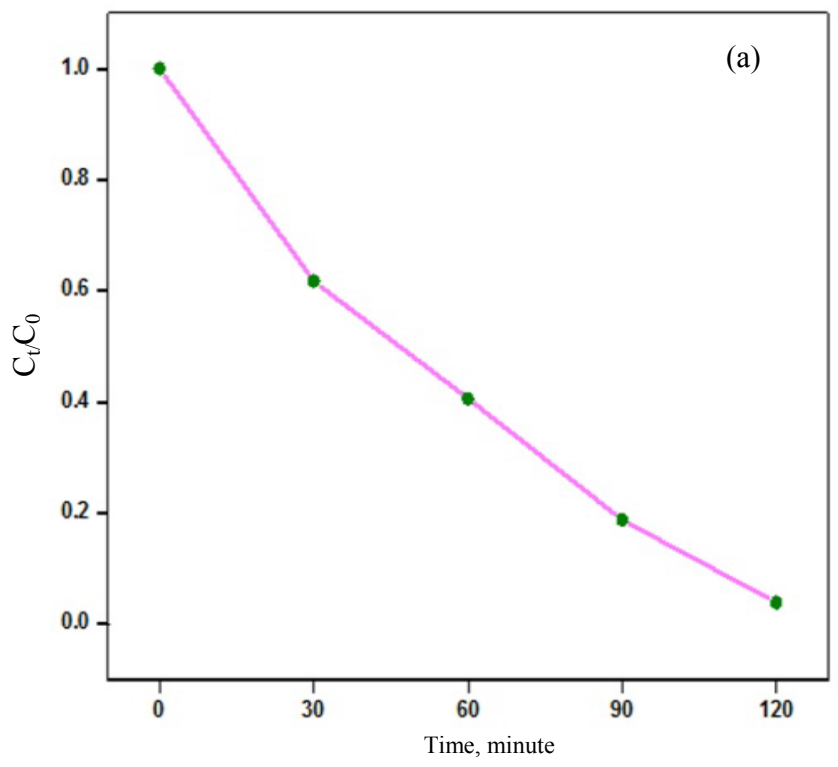




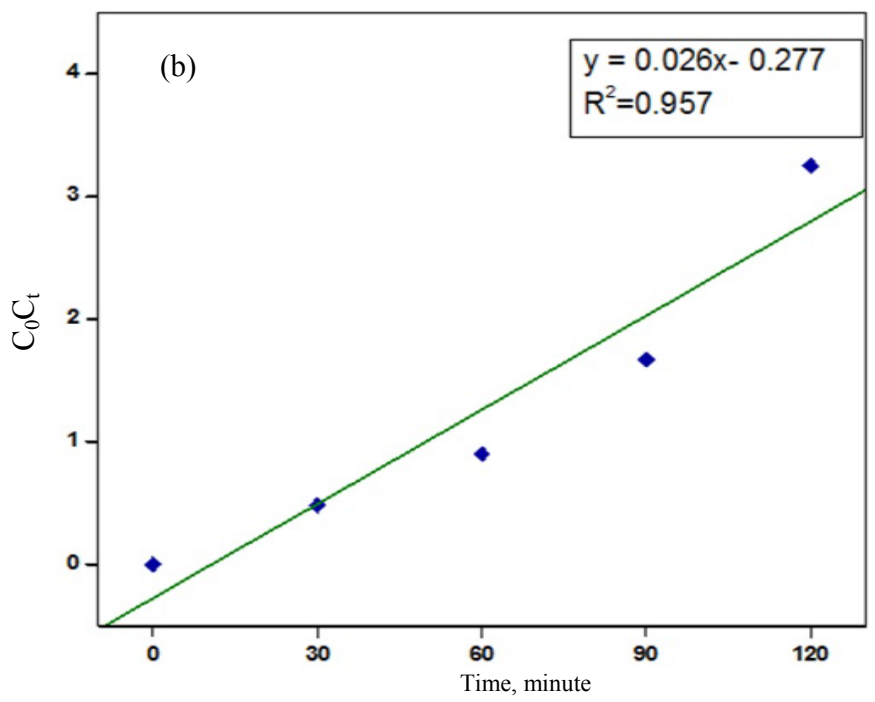

Figure 8. (a,b) Kinetics of MB photodegradation by $\mathrm{ZnO}$ nanoparticle w.r.t. time

\section{Reusability analysis of $\mathrm{ZnO}$ nanoparticles}

It can be clearly seen that the efficiency of the photocatalyst remains high even after four runs. The $\mathrm{ZnO}$ nanoparticles were recovered using centrifugation and washed several times with water and ethanol and then dried in an oven overnight at $100{ }^{\circ} \mathrm{C}$. The recovered $\mathrm{ZnO}$ catalyst is reused for next three runs, which degrades $\mathrm{MB}$ with a minimal decrease in efficiency. This is possibly due to the loss of catalyst during centrifugation.

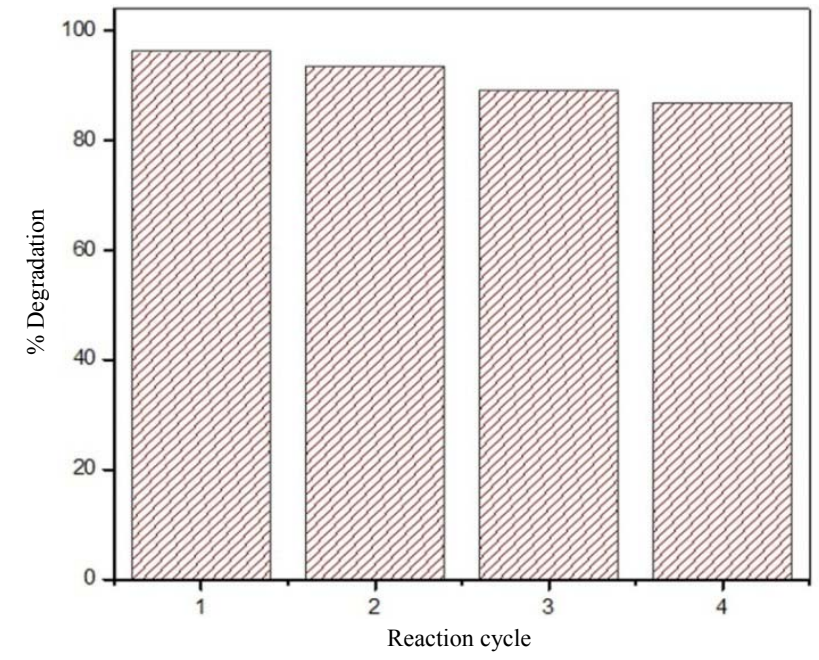

Figure 9. Reusability study of $\mathrm{ZnO}$ nanoparticles for photocatalytic degradation of $\mathrm{MB}$ dye under solar light.

\section{Conclusion}

In summary, $\mathrm{ZnO}$ nanoparticles have been synthesized by using a very feasible modified chemical synthesis. The structural characteristics and its application towards waste water 
treatment have been systematically investigated. The formation of $\mathrm{ZnO}$ nanoparticles was confirmed from XRD, UV-Vis and PL analyses. Thermogravimetric analysis showed high thermal stability of the synthesised material. The TEM micrographs indicated the formation of nanosized $\mathrm{ZnO}$ with reasonably good homogeneity. HREM micrograph confirmed lattice spacing of $0.30 \mathrm{~nm}$ exposing the (100) plane of hexagonal $\mathrm{ZnO}$. The synthesised material displayed significant photo-catalytic performance for $\mathrm{MB}$ dye degradation with superior reusability following a pseudo first order kinetics.

\section{Acknowledgment}

PS and ATM thank DST (New Delhi) for project grant No. SR/FT/CS-69/2011. Authors also thank SAIF, NEHU and USIC, Gauhati University for providing instrumental facilities.

\section{References}

1 Udawatte N, Lee M, Kim J and Lee D, ACS Appl Mater Interfaces, 2011, 3(11), 4531-4538; DOI:10.1021/am201221x

2 Chen G, Sun M, Wei Q, Zhang Y, Zhu B and Du B, J Haz Mater., 2013, 244-245, 86-93; DOI:10.1016/j.jhazmat.2012.11.032

3 Hong T K, Tripathy N, Son H J, Ha K T, Jeong H S and Hahn Y B, J Mater Chem B, 2013, 1, 2985-2992; DOI:10.1039/C3TB20251H

4 Singh A K and Nakate U T, J Nanoparticles, 2013, 2013(310809), 7; DOI:10.1155/2013/310809

5 Hosseinia Z S, Zad A I and Mortezaalia A, Sensors Actuators B, Chem., 2015, 207, 865-871; DOI:10.1016/j.snb.2014.10.085

6 Bresser D, Mueller F, Fiedler M, Krueger S, Kloepsch R, Baither D, Winter M, Paillard E and Passerini S, Chem Mater.. 2013, 25(24), 4977-4985; DOI: $10.1021 / \mathrm{cm} 403443 \mathrm{t}$

7 Wang T, Lv R, Zhang $\mathrm{P}$, Li C and Gong J, Nanoscale, 2015, 7, 77-81; DOI:10.1039/C4NR03735A

8 Kaur J, Kumar P, Sathiaraj T S and Thangaraj R, Int Nano Lett., 2013, 3-4; DOI:10.1186/2228-5326-3-4

9 Jiang D, Cao L, Liu W, Su G, Qu H, Sun Y and Dong B, Nanoscale Res Lett., 2009, 4(1), 78-83; DOI:10.1007/s11671-008-9205-6

10 Lv T, Pan L, Liu X and Sun Z, Catal Sci Technol., 2012, 2, 2297-2301; DOI:10.1039/C2CY20023F

11 Bagabas A, Alshammari A, Aboud M F A and Kosslick H, Nanoscale Res Lett., 2013, 8, 516; DOI:10.1186/1556-276X-8-516

12 Wang Z L, J Phys Condens Matter., 2004, 16, 829.

13 Nagaraja R, Kottam N, Girija C R and Nagabhushana B M, Powder Tech., 2012, 215216, 91-97.

14 Radzimska A K and Jesionowski T, Materials, 2014, 7(4), 2833-2881; DOI:10.3390/ma7042833

15 Moazzen M A M, Borghei S M and Taleshi F, Appl Nanosci., 2013, 3(4), 295-302; DOI:10.1007/s13204-012-0147-z

16 Polsongkram D, Chamninok P, Pukird S, Chow L, Lupan O, Chai G, Khallaf H, Park S and Schulte A, Physica B: Condensed Matter, 2008, 403(19-20), 3713-3717; DOI:10.1016/j.physb.2008.06.020

17 Zhuo R F, Feng H T, Liang Q, Liu J Z, Chen J T, Yan D, Feng J J, Li H J, Cheng S, Geng B S, Xu X Y, Wang J, Wu Z G, Yan P X and Yue G H, J Phys D: Appl Phys., 2008, 41, 185405. 
18 Yang P, Yan H, Mao S, Russo R, Johnson J, Saykally R, Morris N, Pham J, He R and Choi H J, Adv Funct Mater., 2002, 12, 323-331; DOI:10.1002/16163028(20020517)12:5<323::AID-ADFM323>3.0.CO;2-G

19 Tong Y, Liu Y, Shao C, Liu Y, Xu C, Zhang J, Lu Y, Shen D and Fan X, J Phys Chem B, 2006, 110(30), 14714-14718; DOI:10.1021/jp056654h

20 Chakraborty S, Kole A K and Kumbhakar P, Mat Lett., 2012, 67(1), 362-364; DOI:10.1016/j.matlet.2011.10.018

21 Jain N, Bhargava A and Panwar J, Chem Eng J., 2014, 243, 549-555; DOI:10.1016/j.cej.2013.11.085

22 Guttmann P and Ehrlich P, Berliner Klinische Wochenschrift, 1891, 28, 953-956.

23 Wainwright M and Crossley K B, J Chemother., 2002, 14(5), 431-443.

24 Ramsay R R, Dunford C and Gillman P K, Brit J Pharmacol., 2007, 152(6), 946-951; DOI:10.1038/sj.bjp.0707430

25 Cragan J D, Teratology, 1999, 60(1), 42-48; DOI:10.1002/(SICI)10969926(199907)60:1<42::AID-TERA12>3.0.CO;2-Z

$26 \mathrm{Oz} \mathrm{M}$, Isaev D, Lorke D E, Hasan M, Petroianu G and Shippenberg T S, Brit $J$ Pharmacol., 2012, 166(1), 168-176; DOI:10.1111/j.1476-5381.2011.01462.x

27 Khan M A, North A P and Chadwick D R, Ann R Coll Surg Engl., 2007, 89(2), W9-11.

28 Tripathi A and Srivastava S K, Int J Bioscience, Biochemistry and Bioinformatics 2011, 1(1), 37-40; DOI:10.7763/IJBBB.2011.V1.7

29 Chena C, Yua B, Liub P, Liua J F and Wanga L, J Ceramic Process Res., 2011, 12 , 420-425.

30 Bagheri S, Chandrappa K G and Hamid S B A, Der Pharma Chemica, 2013, 5(3), 265-270.

31 Viswanatha R, Venkatesh T G, Vidyasagar C C and Arch Y A N, Appl Sci Res., 2012, 4(1), 480-486.

32 Bindu P and Thomas S, J Theor Appl Phys., 2014, 8(4), 123-134.

33 Willander M, Nur O, Sadaf J R, Qadir M I, Zaman S, Zainelabdin A, Bano N and Hussain I, Materials, 2010, 3(4), 2643-2667; DOI:10.3390/ma3042643

34 Ahn C H, Kim Y Y, Kim D C, Mohanta S K and Cho H K, J Appl Phys., 2009, 105(1), 013502; DOI:10.1063/1.3054175

35 Mishra S K, Srivastava R K, Prakash S G, Yadav R S and Panday A C, Opto Electron Rev., 2010, 18(4), 467-473.

36 Khezrianjoo S and Revanasiddappa H D, J Catal., 2013, 2013(582058), 1.

37 Pung S Y, Lee W P and Aziz A, Int J Inorg Chem., 2012, 2012(608183), 9; DOI:10.1155/2012/608183 